\title{
Permafrost Distribution in Mongolia Under the Scenarios of RCP2.6 and RCP8.5
}

\author{
Saruulzaya Adiya ${ }^{1, *}$, Enkhbat Erdenebat ${ }^{2}$ \\ ${ }^{1}$ Institute of Geography and Geoecology, Mongolian Academy of Sciences, Ulaanbaatar, Mongolia \\ ${ }^{2}$ Information and Research Institute of Meteorology, Hydrology and Environment, Ulaanbaatar, Mongolia \\ *Corresponding author.Email: saruulzayaa@mas.ac.mn
}

\begin{abstract}
We examined the projection of permafrost distribution in Mongolia using RCP2.6 and RCP8.5 scenarios. According to the high emission scenario, an annual average near-surface temperature rapidly increases in Mongolia with high confidence. A similar trend of temperature is obtained at the depth of $3 \mathrm{~m}$. A quantitative analysis of permafrost distribution using a high emission scenario suggests $87.5 \%$ of the current distribution of permafrost is vulnerable to climate change at the end of the century in Mongolia. The distribution of permafrost has a gradual reduction during the first half of the 21 st century. The high emission scenario confirms distribution of permafrost is vulnerable to ongoing climate change and the distribution of permafrost will have major alterations in the second half of the 21 st century in Mongolia.
\end{abstract}

Keywords: Distribution of permafrost, the future trend of permafrost, RCP2.6, RCP8.5, Mongolia

\section{INTRODUCTION}

In the fifth assessment report (AR5) of the Intergovernmental Panel on Climate Change, the global mean surface temperature combined land and ocean surface has changed by $0.85^{\circ} \mathrm{C}$ between 1880 and 2012 [1]. According to the instrumental record, global mean temperatures in the 1980s, 1990s, and 2000s have been successively warmer than all previous decades. Due to climate change, the frequency and intensity of extreme weather events have increased since the 1950s, particularly over Europe, North Asia, and Australia. In Mongolia, the annual mean near-surface temperature was increased by $2.14^{\circ} \mathrm{C}$ during the period between 1940 and 2000 [1].

Permafrost in Mongolia has located on the southern edge of the Siberian permafrost that is the most vulnerable to climate change. The climate change projections, based on several global models, suggest the highest warming corresponds to the highlatitude regions, with some models predicting as high as a $7^{\circ} \mathrm{C}-8^{\circ} \mathrm{C}$ warming over land in those regions by the end of the $21^{\text {st }}$ century [1]. Thus, it is important to conduct a quantitative assessment for the appropriate adaptations and mitigation strategies based on climate change projection.
Although climate change is influencing a variety of sectors, the permafrost might be altered most through the strong relationship between land and atmospheric interaction. Land degradation is affecting permafrost in various ways, tiny thermal insulation of vegetation cover could induce a rapid thawing of the permafrost. Poor management of land, overgrazing, decreasing rainfall and increasing temperature can contribute to land degradation, thus enhancing the loss of permafrost in Mongolia.

Permafrost, covering approximately $24 \%$ of the land area in the Northern Hemisphere, is defined as subsurface earth materials remaining below $0^{\circ} \mathrm{C}$ for two consecutive years [3]. As a product of a cold climate, permafrost is extremely sensitive to climate change. Permafrost controlled by air temperature in the thickness of active layer, presence, and geographic extent reacts sensitively to changes in atmospheric temperature [2]. Thawing permafrost and the resulting microbial decomposition of previously frozen organic carbon is one of the most significant potential feedbacks from terrestrial ecosystems to the atmosphere [4]. It is important to make an adaptation and mitigation plan based on the potential rate of thawing of permafrost with future projections. 
Permafrost in Mongolia is extremely vulnerable to an increasingly warmer climate, which consequently affected the livelihood of the local population and ecosystem within the region. Previous studies have reported permafrost changes in Mongolian region from 2016 to 2099 using the RegCM4-GEM and RegCM-ECHAM5 models [5]. According to RegCM4-GM model simulation, for example, permafrost expected to cover $22.88 \%$ in $2016-2035,10.88 \%$ in $2046-2065$, and $1.48 \%$ in 2080-2099, respectively. In this study, we focus on quantitatively evaluating the spatial and temporal change of permafrost using available future projections for soil temperature in Mongolia. Validating a general circulation model with in-situ data has many challenges such as coarse resolution. Therefore, we mainly focused on the trend of the projection which is the majority of the general circulation models have similar projections [1].

\section{DATA AND MODEL}

MIROC5 (Model for Interdisciplinary Research on Climate version 5) is one of the best CMIP5 GCMs simulating free atmosphere conditions. In this study, we used MIROC5 [3; 6] data for future projection of the soil temperature. The future change of soil temperature obtained during 2020-2100 under Representative Concentration Pathways (RCP) scenarios such as RCP2.6 and RCP8.5 [7]. According to the IPCC, RCP2.6 requires that carbon dioxide emissions start declining globally by 2020 and go to zero by 2100 . In contrast, RCP8.5 emissions continue to rise throughout the 21 st century. MIROC5 adopts an updated version of the land surface model called Minimal Advanced Treatments of Surface Interaction and Runoff, which predicts the temperature and water in six soil layers, one canopy layer, and three snow layers [8]. The soil temperature, $\mathrm{T}_{\mathrm{g}}$, is prognosticated by a thermal conduction equation:

$\operatorname{Cg} \frac{\partial \mathrm{Tg}}{\partial \mathrm{t}}=\frac{\partial \mathrm{Fg}}{\partial \mathrm{z}}=\frac{\partial}{\partial \mathrm{z}} \mathrm{kg} \frac{\partial \mathrm{Tg}}{\partial \mathrm{z}}$

Where $\mathrm{F}_{\mathrm{g}}$ is the soil heat flux, $\mathrm{C}_{\mathrm{g}}$ is the soil heat capacity, and $\mathrm{kg}$ is the soil thermal conductivity. MIROC5 has a soil depth of $0.025 \mathrm{~m}, 0.15 \mathrm{~m}, 0.625$ $\mathrm{m}, 1.5 \mathrm{~m}, 3 \mathrm{~m}$, and $9 \mathrm{~m}$, respectively. The soil temperature at $3 \mathrm{~m}$ depth was analyzed due to small sensitivity in comparison with shallow layers and deep that completely separate from the ground surface in this study. MIROC5 has a resolution of 1.40625 degrees. The spatial resolution of MIROC5 was converted to 0.1 degrees by Bessel interpolation.
The TTOP (temperature on top of permafrost) modeling is used to obtain the distribution of permafrost in Mongolia [9; 10]. The TTOP model maps the average annual temperature of the upper permafrost or the lower limit of seasonal thawing. The TTOP model adopts a spatial resolution of 0.1 degrees in this study.

Specific year in the future projection has a little importance therefore most studies discuss multidecadal averages in studies. In this study, we report temperature projections for 10 -year intervals during 2020-2100 to discuss the decadal variation of the permafrost distribution.

\section{RESULT AND DISCUSSION}

\subsection{Future projection of near-surface temperature}

Figure 1 illustrates near-surface temperature in Mongolia. RCP2.6 scenario has a minor increase of temperature toward the end of the $21 \mathrm{st}$ century. RCP2.6 has a small fluctuation of temperature during 2020-2100 with high uncertainty $\left(R^{2}=0.01\right)$. In contrast, the RCP8.5 scenario suggests a strong increase in the temperature with high confidence $\left(R^{2}\right.$ $=0.8$ ) in Mongolia. RCP projection of MIROC5 reveals that near-surface temperature in Mongolia has a similar increasing trend with global projection [11]. Thus, it is necessary to evaluate the variability of permafrost in Mongolia under the condition of a warming climate.

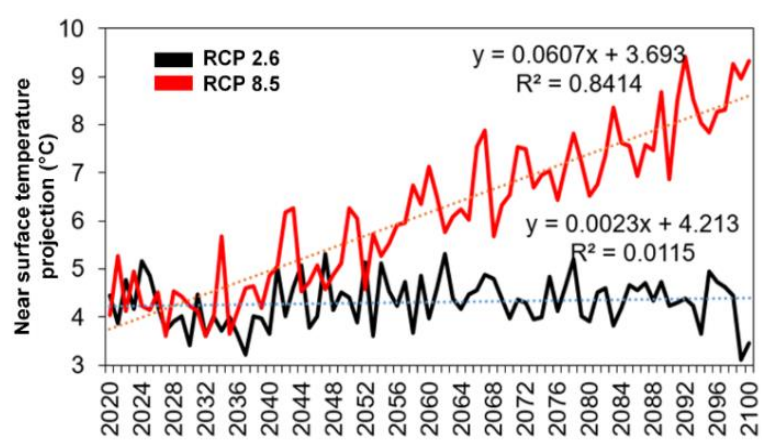

Figure 1. Near-surface temperature projection of RCP2.6 (black line) and RCP8.5 (red line) in Mongolia $\left(42^{\circ} \mathrm{N}-52^{\circ} \mathrm{N}, 90^{\circ} \mathrm{E}-120^{\circ} \mathrm{E}\right)$.

\subsection{Future projection of permafrost}

Figure 2 illustrates the distribution of permafrost by TTOP model. Permafrost is dominantly distributed in Khangai, Khovsgol and Khentii 
mountains and less distribution occurs in Altai mountains. The coldest permafrosts correspond to Khovsgol $\left(-0.66^{\circ} \mathrm{C}\right)$, Khangai $\left(-0.82^{\circ} \mathrm{C}\right)$ and Altai (0.83 ) mountain ranges. Permafrost in Khentii ($0.34^{\circ} \mathrm{C}$ ) mountain is less cold therefore more vulnerable to climate change.

The future projection of the soil temperature at $3 \mathrm{~m}$ by the scenario of $\mathrm{RCP} 2.6$ and $\mathrm{RCP} 8.5$ is illustrated in Figure 3. Two scenarios are shown distinct differences for soil temperature variation. RCP8.5 scenarios suggest that at the end of the 21st century $(2091-2100)$, area-averaged $\left(90^{\circ} \mathrm{E}-\right.$ $120^{\circ} \mathrm{E}, 42^{\circ} \mathrm{N}-52^{\circ} \mathrm{N}$ ) soil temperature at $3 \mathrm{~m}$ could be risen by $4.2^{\circ} \mathrm{C}$ in comparison with the current average temperature (2011-2020) in Mongolia. On the other hand, RCP2.6 suggests modest change (risen by $0.6^{\circ} \mathrm{C}$ ) of the climate in Mongolia for the same period.

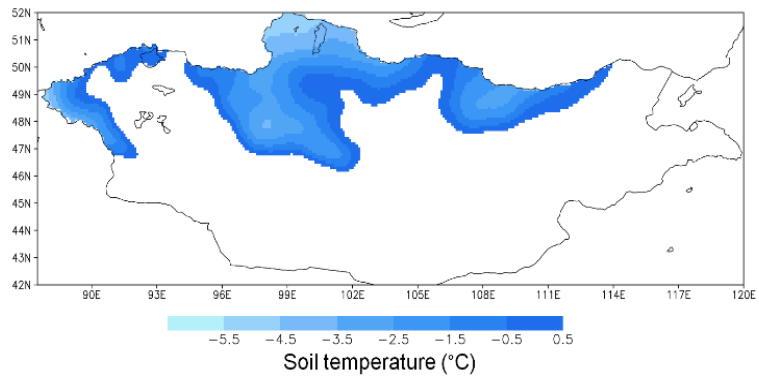

Figure 2. Permafrost distribution in Mongolia using TTOP model.

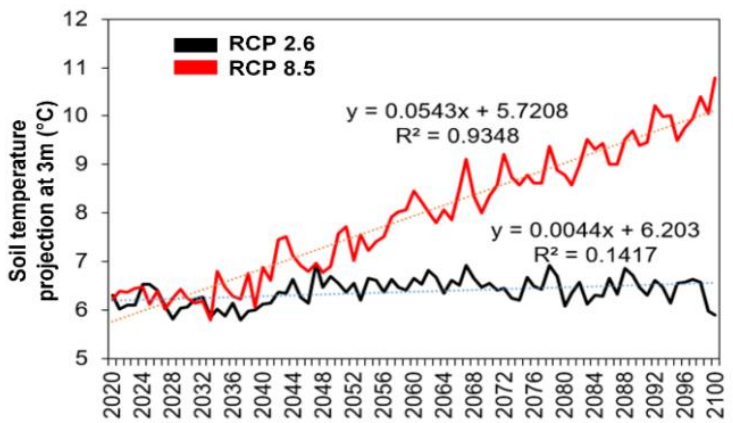

Figure 3. RCP2.6 (black line) and RCP8.5 (red line) projections for area-averaged $\left(90^{\circ} \mathrm{E}-120^{\circ} \mathrm{E}, 42^{\circ} \mathrm{N}-\right.$

$52^{\circ} \mathrm{N}$ ) soil temperature at $3 \mathrm{~m}$.

Under the RCP2.6 scenario, soil temperature at $3 \mathrm{~m}$ has a moderate change at the end of the $21 \mathrm{st}$ century (Figure 3). Figure 4 illustrates the distribution of permafrost change under RCP2.6 scenario. A change of permafrost is obtained when the decadal mean temperature of future projection is subtracted by the current (2010-2020) average temperature. Therefore, a systematic bias of the MIROC5 model has less impact on the study result. The highest loss of permafrost could occur in the middle of the $21 \mathrm{st}$ century by $27.3 \%, 29.9 \%$ and $26.6 \%$ in Figure 4 (d, e and f) respectively. The most permafrost losses correspond to the Khangai and Khentii mountain areas. Permafrost in Altai Mountain, under the RCP projections, is persistent and long-lasting permafrost than other regions. Under the scenario of RCP2.6, permafrost distribution regains the same level as the current climate condition at the end of the $21 \mathrm{st}$ century.

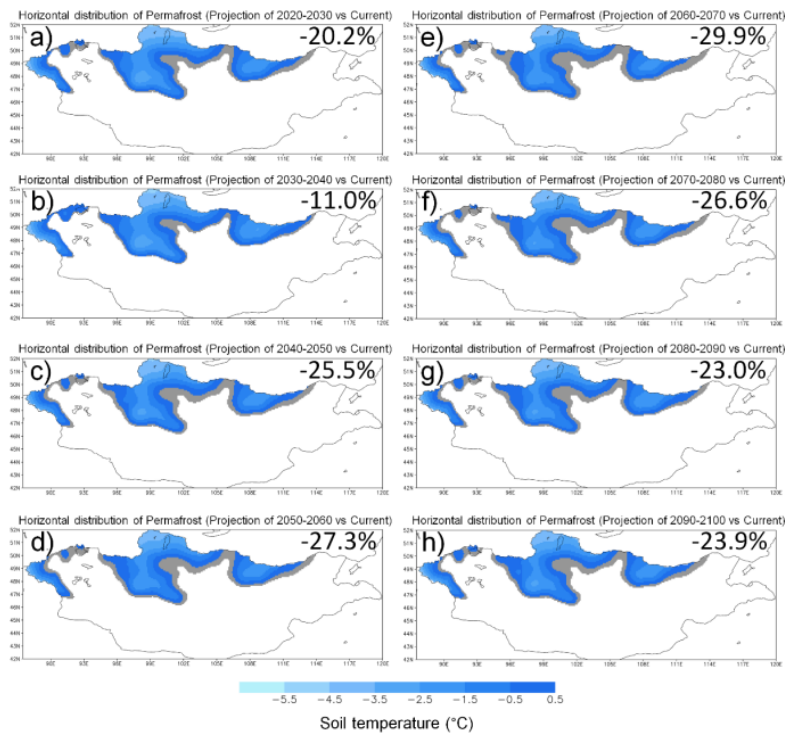

Figure 4. Permafrost change by RCP2.6 scenario in Mongolia. Gray color indicates the current distribution of permafrost; blue color indicates the distribution of permafrost for the corresponding decades. Numbers on the top right indicate the percentage of permafrost reduction in comparison with the current (2010-2020) distribution of permafrost.

According to the RCP8.5 scenario, area-averaged soil temperature will rapidly increase toward the end of 21st century in Mongolia in Figure 3. Figure 5 indicates the rapid increase of area-averaged soil temperature is closely corresponds to the loss of distribution of the permafrost in Mongolia. Loss of permafrost distribution is moderate in the first two decades and increased loss of permafrost distribution is estimated for the subsequent decades. The first substantial decrease of permafrost distribution corresponds to $-38.4 \%$ (Figure $5 \mathrm{c}$ ) comparisons with the current distribution in Mongolia. Permafrost in Khentii Mountain will be the first to be lost completely in Mongolia (Figure 5g). RCP8.5 scenario suggests that up to $87.5 \%$ of the total area of permafrost has a potential loss due to climate change in Mongolia (Figure 5h). 
This study focused on quantitatively evaluates permafrost distribution using future projection. The study suggests distribution of permafrost varies by decades. The study did not intend to experiment on permafrost in Mongolia therefore there is no need to perform modeling simulation in order to evaluate future projection of permafrost.

This study lacks ensemble members of future projections and horizontal resolution of the model. Further examination is needed to investigate the middle of the century where the sudden increase of permafrost loss was obtained in Mongolia.

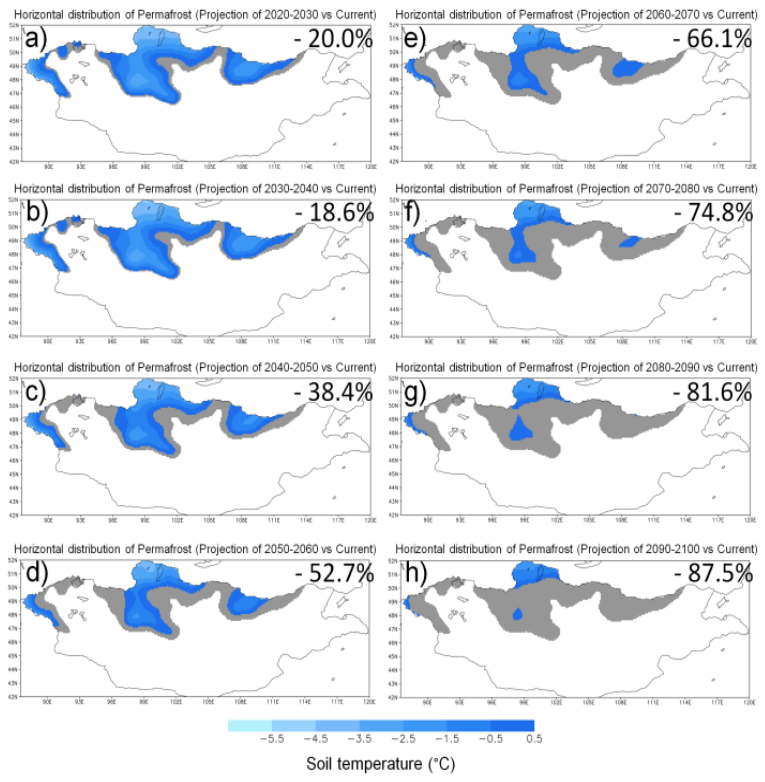

Figure 5. Same as Figure 4 but for the RCP8.5 scenario

\section{CONCLUSIONS}

We quantitatively evaluate the future distribution of permafrost using RCP2.6 and RCP8.5 scenarios in Mongolia. We found that permafrost in Khentii Mountain is most vulnerable in the region. Robust and widespread permafrost was identified in Altai, Khangai and Khovsgol Mountain with soil temperature ranging from $-0.6^{\circ} \mathrm{C}$ to $-0.8^{\circ} \mathrm{C}$. The least influence obtained for the distribution of permafrost by RCP2.6 scenario and distribution of permafrost mostly comparable to the current distribution of permafrost at the end of 21 century. In the middle of the 21st century, the most of reducing permafrost are corresponding to Khangai and Khentii Mountain by the scenario of RCP2.6. In contrast, RCP8.5 reveals the highest impact on the distribution of permafrost in Mongolia. The first major reduction of permafrost ($38.4 \%$ ) is obtained in the decade of the 2040s thus; the decade of 2040s could be the key decade to make afford to maintain the distribution of permafrost in Mongolia. Permafrost in Khentii Mountain may be melt completely and total loss of permafrost coverage in Mongolia might reach up to $87.5 \%$ at the end of the 21 st century in comparison to current permafrost distribution. This study suggests that there are two different paces of permafrost loss for the early and latter part of the century by the RCP 8.5 scenario.

\section{ACKNOWLEDGMENTS}

This research work was carried out under "Responses of permafrost to climate change and their ecological impacts on the Mongolian Plateau" project. The project has been implemented by The Division of Permafrost Study, Institute of Geography and Geoecology (IGG), Mongolian Academy of Sciences (MAS) which is funded by the Mongolian Foundation for Science and Technology (2019013).

\section{REFERENCES}

[1] Hartmann DL et al., (2013). Observations: Atmosphere and Surface. In: Climate Change 2013: The Physical Science Basis. Contribution of Working Group I to the Fifth Assessment Report of the Intergovernmental Panel on Climate Change [Stocker, T.F., D. Qin, G.-K. Plattner, M. Tignor, S.K. Allen, J. Boschung, A. Nauels, Y. Xia, V. Bex and P.M. Midgley (eds.)]. Cambridge University Press, Cambridge, United Kingdom and New York, NY, USA.

[2] A.L. Washburn, (1979). Geocryology-A survey of Periglacial Processes and Environments, John and Wiley Sons Press, New York,. pp. 496.

[3] E.A.G. Schuur, J. Bockheim, J. Canadell, et al., (2008). Vulnerability of permafrost carbon to climate change: implications for the global carbon cycle, Bioscience 58 (8) pp701-714. DOI: https://doi.org/10.1641/B580807

[4] Saruulzaya Adiya, Sainbayar Dalantai, Tonghua $\mathrm{Wu}$, Xiaodong Wu, Jambaljav Yamkhin, Yuhai Bao, Erdenesukh Sumiya, Gansukh Yadamsuren, Dashtseren Avirmed, Battogtokh Dorjgotov. (2021). Spatial and temporal change patterns of near-surface $\mathrm{CO} 2$ and $\mathrm{CH} 4$ concentrations in different permafrost regions on the Mongolian Plateau from 2010 to 2017. Science of the Total Environment. Vol 800, (2021) 149433. DOI: https://doi.org/10.1016/j.scitotenv.2021.149433 
[5] Ya. Jambaljav, (2017). Permafrost distribution and its changes in Mongolia. Ulaanbaatar, Mongolia. ISBN: 978-99962-1-035-8. Pp 1-80.

[6] Watanabe, M., Suzuki, T., O’ishi, R., Komuro, Y., Watanabe, S., Emori, S., Takemura, T., Chikira, M., Ogura, T., Sekiguchi, M. and Takata, K., (2010). Improved climate simulation by MIROC5: Mean states, variability, and climate sensitivity. Journal of Climate, 23(23), pp 6312-6335. DOI: https://doi.org/10.1175/2010JCLI3679.1

[7] Collins, M., R. Knutti, J. Arblaster, J.-L. Dufresne, T. Fichefet, P. Friedlingstein, X. Gao, W.J. Gutowski, T. Johns, G. Krinner, M. Shongwe, C. Tebaldi, A.J. Weaver and M. Wehner, (2013). Long-term Climate Change: Projections, Commitments and Irreversibility. In: Climate Change 2013: The Physical Science Basis. Contribution of Working Group I to the Fifth Assessment Report of the Intergovernmental Panel on Climate Change [Stocker, T.F., D. Qin, G.-K. Plattner, M. Tignor, S.K. Allen, J. Boschung, A. Nauels, Y. Xia, V. Bex and P.M. Midgley (eds.)]. Cambridge
University Press, Cambridge, United Kingdom and New York, NY, USA.

[8] Takata, K., Emori, S. and Watanabe, T., (2003). Development of the minimal advanced treatments of surface interaction and runoff. Global and planetary Change, 38(1-2), pp 209222. DOI: https://doi.org/10.1016/S09218181(03)00030-4

[9] Riseborough, D.W., and M.W. Smith 1998. Exploring the limits of permafrost. Permafrost: Seventh International Conference, Yellowknife, Canada, Proceedings: pp 935-942. Edited by A.G.Lewkowicz and M.Allard. Nordicana, Quebec.

[10] Smith, M.W., and D.W. Riseborough (1996). Permafrost Monitoring and Detection of Climate Change, Permafrost and Periglacial Processes, Vol 7: 301-309. DOI: https://doi.org/10.1002/(SICI)10991530(199610)7:4<301::AID-PPP231>3.0.CO;2$\mathrm{R}$

[11]IPCC Intergovernmental Panel on Climate Change, (2019). 